\title{
AVALIAÇÃo DO VIGOR DE SEMENTES DE MELÃO PELO TESTE DE DETERIORAÇÃo CONTROLADA ${ }^{1}$
}

\author{
MARIA CARMEN BHERING ${ }^{2}$; DENISE CUNHA FERNANDES S. DIAS ${ }^{3}$; DAI TOKUHISA ${ }^{4}$; \\ LUIZ ANTÔNIO DOS SANTOS DIAS ${ }^{5}$
}

\begin{abstract}
RESUMO - O trabalho teve como objetivo determinar a eficiência do teste de deterioração controlada para avaliar o vigor de sementes de melão (Cucumis melo L.). Inicialmente, sementes de quatro lotes do híbrido Golden Mine tiveram o seu teor de água ajustado para 20 e $24 \%$. Foram então submetidas à deterioração controlada em banho Maria, a $45^{\circ} \mathrm{C}$, por 24 e 48 horas. Os resultados obtidos foram relacionados aos de germinação, primeira contagem de germinação, germinação a baixa temperatura, emergência de plântulas em solo e comprimento médio de plântula. Os resultados indicaram que a deterioração controlada a $45^{\circ} \mathrm{C}$ por 48 horas, utilizando-se sementes com grau de umidade de $24 \%$, foi o procedimento mais eficiente para a separação dos lotes em níveis de vigor.
\end{abstract}

Termos para indexação: Cucumis melo, qualidade fisiológica, análise de sementes.

\section{VIGOR EVALUATION OF MELON SEEDS BY CONTROLLED DETERIORATION TEST}

\begin{abstract}
The objective of this study was to determine the efficacy of the controlled deterioration test for the evaluation of melon seed vigor. Four seed lots of the Golden Mine hybrid with two moisture content levels (20 and 24\%) were submitted to controlled deterioration, at $45^{\circ} \mathrm{C}$, for 24 and 48 hours. The results were related to germination, first count, cool germination, seedling emergence and seedling length tests. It was concluded that the controlled deterioration test was efficient to determine different vigor levels of melon seeds. The controlled deterioration test, performed at $45^{\circ} \mathrm{C}$ for 48 hours, with seeds at $24 \%$ moisture content, was the most efficient to indicate seed vigor levels.
\end{abstract}

Index terms: Cucumis melo, physiological quality, seed analysis.

\section{INTRODUÇÃO}

A determinação do potencial fisiológico das sementes somente é consistente quando as informações fornecidas pelo teste de germinação são complementadas pela avaliação do vigor. Estes, além de possibilitarem selecionar os melhores lotes para a comercialização, fornecem estimativa do desempenho das sementes após a semeadura em campo e/ou durante o armazenamento detectando, principalmente, as diferenças entre lotes com capacidade de germinação semelhante. Assim, os testes de

\footnotetext{
${ }^{1}$ Submetido em 03/09/2003. Aprovado em 21/02/2004

2 Pesquisador M.S., Departamento de Fitotecnia, Universidade Federal de Viçosa, 36571-000 - Viçosa, MG.

3 Professor Adjunto IV, Departamento de Fitotecnia, Universidade Federal de Viçosa, 36571-000 - Viçosa, MG.

${ }^{4}$ Estudante de Agronomia da Universidade Federal de Viçosa, 36571000 - Viçosa, MG.

${ }^{5}$ Pesquisador DS, DBG/BIOAGRO, Universidade Federal de Viçosa, 36571-000 - Viçosa, MG.
}

vigor são componentes essenciais de programas de controle de qualidade nas empresas de sementes. De acordo com Marcos Filho (1999), as informações sobre o vigor são ainda mais importantes para sementes de elevado valor comercial, como as hortaliças, dentre as quais inclui-se o melão.

Dentre os testes de vigor disponíveis na atualidade, destaca-se o teste de deterioração controlada, desenvolvido inicialmente para avaliar a qualidade de sementes pequenas (Powell \& Matthews, 1981), baseando-se em técnica de envelhecimento similar à do teste de envelhecimento acelerado. Neste teste, as sementes são submetidas a alta temperatura e umidade relativa do ar por período de tempo determinado, condições que favorecem o seu umedecimento. No entanto, a absorção de água com velocidades distintas entre amostras da mesma espécie durante o período de envelhecimento, resulta em diferentes graus de deterioração. No teste de deterioração controlada, o grau de umidade das sementes é ajustado para um mesmo nível, em todas as amostras e, somente após esse 
procedimento, são submetidas a um período de deterioração sob alta temperatura (Matthews, 1980; Hampton \& Tekrony, 1995; Krzyzanowski \& Vieira, 1999). Assim, através deste método é possível se obter um controle mais preciso dos fatores temperatura e teor de água da semente, de modo que as condições do testes são impostas de maneira uniforme para todas as amostras avaliadas.

Segundo Krzyzanowski \& Vieira (1999), a deterioração controlada permite diferenciar lotes de sementes que se encontram em diferentes estádios de deterioração, mas que apresentam percentuais de germinação semelhantes. Assim, o teste tem sido utilizado para detectar diferenças no vigor de lotes de sementes e para avaliar o potencial de armazenamento de sementes de diversas hortaliças, como cebola e brássicas (Powell \& Matthews, 1984), cenoura e alface (Mattews \& Powell, 1987), pimentão (Panobianco e Marcos Filho, 1998), brócolis (Mendonça et al., 2000 e Mendonça et al., 2003). Segundo Matthews (1980), os resultados deste teste apresentam ainda boa correlação com a emergência das plântulas em campo.

O grau de umidade a ser atingido no teste de deterioração controlada bem como as condições de temperatura mais indicadas para sementes de diversas espécies foram relacionadas por Matthews \& Powell (1987), Wang et al. (1994) e Krzyzanowski \& Vieira (1999). Bhering et al. (2000) verificaram que o teste de deterioração controlada embora não tenha sido o mais eficiente para avaliar o vigor de sementes de pepino, quando conduzido com sementes com $24 \%$ de água, a $45^{\circ} \mathrm{C}$, por 48 horas, permitiu identificar o lote de menor vigor. Em trabalho com sementes de brócolis, Mendonça et al. (2000) observaram diferenças na qualidade das sementes da cultivar Piracicaba Precoce pelo teste de deterioração controlada a 40 e $44^{\circ} \mathrm{C}$ em sementes com diferentes teores de água. Em outro trabalho, Mendonça et al. (2003), ao submeterem sementes de brócolis com 18, 20, 21, 23 e 24\% de água à deterioração controlada a $45^{\circ} \mathrm{C}$ por 24 horas, verificaram que em todos os teores de água estudados, houve separação dos lotes quanto ao vigor. Torres (2002) empregou o teste de deterioração a $45^{\circ} \mathrm{C}$ durante 24 e 48 horas em sementes de melão com 18, 21 e $24 \%$ de água e verificou que o procedimento mais adequado para avaliar o potencial fisiológico dos lotes foi a combinação $24 \%$ de teor de água a $45^{\circ} \mathrm{C}$ por 24 horas.

Portanto, o método da deterioração controlada vem sendo testado utilizando-se sementes com teores de água que variam entre 18 e $24 \%$, temperatura geralmente de $45^{\circ}$ $\mathrm{C}$ e períodos de tempo de 24 e 48 horas. Diante do exposto, o trabalho tem como objetivo testar a eficiência do teste de deterioração controlada para avaliar o vigor de sementes de melão.

\section{MATERIAL E MÉTODOS}

O trabalho foi conduzido no Laboratório de Pesquisa em Sementes do Departamento de Fitotecnia da UFV, utilizando-se quatro lotes de sementes de melão, do híbrido Golden Mine. Foram realizados os seguintes testes para avaliar a qualidade das sementes: - germinação - realizado com quatro subamostras de 50 sementes, semeadas em rolo de papel toalha umedecido com quantidade de água equivalente a 2,5 vezes o peso do substrato seco e colocadas em germinador a $25^{\circ} \mathrm{C}$. As avaliações foram realizadas aos quatro e oito dias após a semeadura, seguindo os critérios estabelecidos nas Regras para Análise de Sementes - RAS (Brasil, 1992); primeira contagem de germinação constituiu no registro da percentagem de plântulas normais obtidas no quarto dia após a semeadura do teste de germinação; germinação a baixa temperatura - adotou-se a metodologia recomendada pela AOSA (1983) e descrita por Dias \& Alvarenga (1999). O substrato papel toalha foi umedecido conforme descrito para o teste de germinação e mantido a $18^{\circ} \mathrm{C}$ durante 24 horas. Em seguida, foi realizada a semeadura de quatro subamostras de 50 sementes, sendo preparados os rolos que foram acondicionados em sacos plásticos e mantidos a $18^{\circ} \mathrm{C}$ em incubadora do tipo BOD. Foi realizada apenas uma contagem aos cinco dias após a semeadura, considerando-se como normais aquelas plântulas que apresentavam comprimento igual ou acima de $4 \mathrm{~cm}$. Os resultados foram expressos em percentagem; emergência de plântulas- conduzido em cada de vegetação e utilizando-se bandejas plásticas contendo mistura de solo e areia, na proporção de 1:1. Quatro subamostras de 50 sementes foram distribuídas em sulcos longitudinais de $2 \mathrm{~cm}$ de profundidade distanciados de $5 \mathrm{~cm}$ entre si. Foram feitas irrigações sempre que necessário. A avaliação foi realizada aos 14 dias após a semeadura computando-se a porcentagem de plântulas emergidas por lote; comprimento de plântula - quatro subamostras de 25 sementes foram distuibuídas em uma linha traçada no terço superior do papel toalha (Germitest) previamente umedecido com água, conforme descrito para o teste de germinação. Foram preparados rolos mantidos no interior de sacos plásticos, em incubadora BOD, a $25^{\circ} \mathrm{C}$ (AOSA, 1983; Nakagawa, 1999). O comprimento das plântulas foi avaliado, em $\mathrm{cm}$, com o auxílio de uma régua, no quarto dia após a semeadura. Calculou-se o comprimento médio por plântula, ( $\mathrm{cm} /$ plântula), dividindo-se o somatório dos valores obtidos pelo número de sementes semeadas (25); deterioração controlada - realizado de acordo com metodologia descrita por Powell (1995). Inicialmente, o teor de água das sementes foi elevado para 20 e $24 \%$, distribuindo-se 250 sementes sobre papel toalha umedecido em caixas plásticas $(11 \mathrm{~cm} \times 11 \mathrm{~cm} \times 3 \mathrm{~m})$, conhecidas por 
gerbox, mantidas em germinador a $25^{\circ} \mathrm{C}$. Durante o umedecimento, o grau de umidade das sementes foi monitorado através da realização de pesagens sucessivas (Hampton \& Tekrony, 1995), com intervalos de 20 minutos, até se obter o valor desejado. Em seguida, as sementes de cada amostra foram colocadas em sacos aluminizados, que foram vedados em uma seladora e mantidos em geladeira a $10^{\circ} \mathrm{C}$ por 24 horas. Após este período, as embalagens contendo as sementes permaneceram em banho-maria a $45^{\circ} \mathrm{C}$, onde permaneceram por 24 e 48 horas. Ao serem retirados do banho-maria, as embalagens aluminizadas foram colocadas em recipiente contendo água, por 30 minutos, para redução da temperatura, sendo instalado, em seguida, o teste de germinação conforme metodologia já descrita. As contagens foram realizadas aos sete dias após a semeadura; grau de umidade - foi determinado inicialmente e após cada período de deterioração controlada, pelo método da estufa a $105^{\circ} \mathrm{C} \pm 3$ durante 24 horas, utilizando-se duas subamostras para cada lote, conforme as RAS (Brasil, 1992), sendo os resultados expressos em porcentagem (b.u).

$\mathrm{O}$ delineamento experimental utilizado foi $\mathrm{o}$ inteiramente casualizado com quatro repetições. Os dados foram submetidos a testes de normalidade que indicaram a não necessidade de transformação. Para comparação das médias obtidas nos testes utilizou-se o teste de Tukey, a 5\% de probabilidade. Foram calculados ainda os coeficientes de correlação simples de Pearson (r) entre os resultados dos testes de deterioração controlada e os dos demais testes empregados, sendo a significância dos valores de $r$ determinada pelo teste t a $1 \%$ e $5 \%$ de probabilidade.

\section{RESULTADOS E DISCUSSÃO}

Os resultados obtidos nos testes realizados para caracterizar a qualidade inicial dos lotes encontram-se na Tabela 1. Verifica-se que a germinação dos lotes 1,2 e 3 foi semelhante entre si e superior à do lote 4 , o que também foi observado no teste de emergência de plântulas. No entanto, quando se observam os valores numéricos obtidos nestes dois testes, é possível constatar que, em laboratório, os valores percentuais obtidos foram superiores, o que já era de certo modo esperado já que as condições do teste de germinação são teoricamente ideais para a espécie.

TABELA 1. Porcentagens médias obtidas nos testes de germinação (TG), primeira contagem da germinação (PCG), comprimento de plântula (CP), germinação a baixa temperatura (GBT) e emergência das plântulas em solo (ES) para os quatro lotes de sementes de melão.

\begin{tabular}{cccccc}
\hline LOTES & TG $(\%)$ & PCG $(\%)$ & GBT $(\%)$ & ES (\%) & CP (cm/plântula) \\
\hline 1 & $84 \mathrm{~A}$ & $52 \mathrm{AB}$ & $50 \mathrm{~B}$ & $68 \mathrm{~A}$ & $13,18 \mathrm{~B}$ \\
2 & $89 \mathrm{~A}$ & $63 \mathrm{~A}$ & $77 \mathrm{~A}$ & $68 \mathrm{~A}$ & $20,38 \mathrm{~A}$ \\
3 & $82 \mathrm{~A}$ & $60 \mathrm{~A}$ & $58 \mathrm{~B}$ & $65 \mathrm{~A}$ & $16,75 \mathrm{AB}$ \\
4 & $80 \mathrm{~A}$ & $46 \mathrm{~B}$ & $24 \mathrm{C}$ & $46 \mathrm{~B}$ & $13,03 \mathrm{~B}$ \\
\hline C.V. $(\%)$ & 7,5 & 12,3 & 14,4 & 12,5 & 18,1 \\
\hline
\end{tabular}

Comparação de médias dentro de cada coluna (teste de Tukey, a 5\% de probabilidade).

Quando as sementes foram colocadas para germinar sob condições sub-ótimas de temperatura (Tabela 1), observam-se diferenças entre os lotes 1,2 e 3, não detectadas pelos testes de germinação e de emergência de plântulas em solo. As sementes do lote 2 tiveram desempenho significativamente superior às dos lotes 1 e 3 , permanecendo o lote 4 como inferior aos demais. Assim, este teste foi adequado para classificar os lotes de sementes de melão em níveis de vigor. Para Bhering et al. (2000), o teste de germinação a baixa temperatura $\left(18^{\circ} \mathrm{C}\right)$ não constituiu método eficiente para avaliar o vigor de sementes de pepino, indicando apenas o lote de pior qualidade.

Ainda na Tabela 1, verifica-se que as sementes do lote 2 originaram plântulas com maior comprimento sendo que plântulas menos desenvolvidas foram observadas para os lotes 1 e 4 . Assim, pelos resultados de primeira contagem de germinação, germinação a baixa temperatura e comprimento de plântula observou-se melhor desempenho para as sementes de lote 2, o que não foi constatado nos testes de germinação e emergência de plântulas em solo. Uma das principais finalidades dos testes de vigor é detectar diferenças no desempenho de lotes que apresentam germinação semelhante (Marcos Filho, 1999).

A condução do teste de deterioração controlada a $45^{\circ} \mathrm{C}$ por 24 horas (Tabela 2 ) forneceu, em geral, resultados semelhantes quanto à classificação dos lotes tanto para sementes com $20 \%$ como com $24 \%$ de água, onde o lote 4 foi significativamente inferior aos demais, apesar deste lote não ter diferido estatisticamente do lote 3 , para as sementes com teor de água de $24 \%$. Assim, de modo geral, o período de 24 horas possibilitou separar os lotes em dois níveis distintos de vigor, ou seja, os lotes 1,2 e 3 como os de melhor desempenho e o lote 4 como inferior, independentemente do teor de água das sementes. Torres (2002), avaliando diferentes condições de deterioração controlada em sementes de melão, verificou que a combinação entre teor de água das sementes (24\%), 
temperatura de $45^{\circ} \mathrm{C}$ e período de 24 horas mostrou sensibilidade suficiente para a avaliação do potencial fisiológico das sementes, o que também foi constatado por Panobianco \& Marcos Filho (2001) em sementes de tomate.

TABELA 2. Percentagens médias de plântulas normais (\%) obtidas no teste de deterioração controlada, a $45^{\circ} \mathrm{C}$ por 24 e 48 horas, para os quatro lotes de sementes de melão com teores de água de $20 \%$ e $24 \%$.

\begin{tabular}{clllll}
\hline \multirow{2}{*}{ LOTES } & \multicolumn{4}{c}{ Plântulas normais (\%) } \\
\cline { 2 - 3 } & \multicolumn{2}{c}{ Teor de água 20\% } & & \multicolumn{2}{c}{ Teor de água 24\% } \\
\cline { 2 - 3 } \cline { 5 - 6 } & $24 \mathrm{~h}$ & $48 \mathrm{~h}$ & & $24 \mathrm{~h}$ & $48 \mathrm{~h}$ \\
\hline 1 & $84 \mathrm{~A}$ & $77 \mathrm{AB}$ & & $79 \mathrm{~A}$ & $80 \mathrm{AB}$ \\
2 & $86 \mathrm{~A}$ & $93 \mathrm{~A}$ & & $83 \mathrm{~A}$ & $86 \mathrm{~A}$ \\
3 & $82 \mathrm{~A}$ & $66 \mathrm{BC}$ & & $74 \mathrm{AB}$ & $64 \mathrm{~B}$ \\
4 & $60 \mathrm{~B}$ & $53 \mathrm{C}$ & & $56 \mathrm{~B}$ & $44 \mathrm{C}$ \\
\hline C.V. (\%) & 8,3 & 13,2 & & 14,7 & 12,5 \\
\hline
\end{tabular}

Comparação de médias dentro de cada coluna (teste de Tukey, a 5\% de probabilidade)

Quando o período de deterioração controlada foi aumentado para 48 horas, verificou-se comportamento diferenciado para os lotes 1,2 e 3 , o que não havia sido detectado nos testes conduzidos por 24 horas. A combinação de $45^{\circ} \mathrm{C}, 48$ horas e $20 \%$ de teor de água nas sementes promoveu níveis distintos de deterioração para os quatro lotes, de modo que o lote 2 exibiu maior tolerância às condições de estresse impostas pelo teste, sendo, portanto, um lote de vigor mais elevado. Nestas condições, observa-se que o lote 2 foi superior, embora significativamente não tenha diferido do lote 1. Em geral, os lotes 1 e 3 podem ser classificados como de qualidade intermediária e o lote 4 como de menor vigor, o qual não diferiu significativamente do lote 3 .

Quando sementes com $24 \%$ de água foram submetidas à deterioração controlada por 48 horas, o lote 2 foi identificado como o de melhor desempenho seguido pelos lotes 1 e 3 , enquanto o lote 4 teve o pior desempenho. Esta classificação foi semelhante à obtida no teste de germinação a baixa temperatura. Assim, a deterioração controlada conduzida a $45^{\circ} \mathrm{C}$ por 48 horas, em sementes com teor de água de $24 \%$ mostrou ser um procedimento eficiente para identificar lotes com diferentes potenciais fisiológicos. Em trabalho com sementes de pepino, Bhering et al. (2000) verificaram que embora o teste de deterioração controlada não tenha sido o mais eficiente para avaliar o vigor das sementes, quando conduzido com sementes com teor de água ajustado para $24 \%$, a $45^{\circ} \mathrm{C}$ por 48 horas, foi eficiente para identificar o lote de menor vigor.

Verifica-se que, para as sementes com $20 \%$ de umidade, o período de 24 horas de deterioração não resultou em redução na porcentagem de germinação, quando comparado aos valores obtidos no teste padrão de germinação, especialmente para os lotes de melhor qualidade, ou seja, lotes 1,2 e 3 . Apenas as sementes do lote 4 exibiram sensibilidade a esta condição de deterioração, apresentando redução na germinação de $78 \%$ para $60 \%$. Portanto, esta condição parece não ter sido suficiente para provocar a deterioração das sementes dos lotes 1,2 e 3.

Vale ressaltar que o grau de umidade inicial das sementes variou entre 8,5 e $8,9 \%$ e que, após o teste de deterioração controlada os teores de água permaneceram próximos aos estabelecidos para a condução do teste, ou seja, $20( \pm 0,5 \%)$ e $24 \%( \pm 0,4 \%)$.

Pela análise de correlação (Tabela 3) verifica-se que a deterioração controlada por $24 \mathrm{~h}$ em sementes com $20 \%$ e por 48 horas em sementes com $24 \%$ de umidade foram os únicos procedimentos que se correlacionaram significativamente com os demais testes utilizados para a avaliação do potencial fisiológico das sementes. No entanto, na maioria dos testes conduzidos constatou-se melhor desempenho para as sementes de lote 2, o que só não foi observado nos testes de germinação, emergência de plântulas e deterioração controlada por 24 horas em sementes com teor de água de $20 \%$.

TABELA 3. Coeficientes de correlação simples (r) entre os resultados obtidos nos testes de deterioração controlada (DC) e de germinação (TG), primeira contagem de germinação (PC), germinação a baixa temperatura (GBT), emergência das plântulas em solo (ES) e comprimento de plântula $(\mathrm{CP})$ realizados com as sementes dos quatro lotes de melão.

\begin{tabular}{llccc}
\hline & \multicolumn{4}{c}{ Coeficientes de correlação simples (r) } \\
\cline { 2 - 5 } & \multicolumn{1}{c}{ DC } & DC & DC & DC \\
& $20 \% / 24 h$ & $24 \% / 24 h$ & $20 \% / 48 h$ & $24 \% / 48 h$ \\
\hline TG & $0,74^{*}$ & $0,65^{*}$ & $0,72^{*}$ & $0,81^{* *}$ \\
PC & $0,71^{*}$ & 0,56 & 0,53 & $0,74^{*}$ \\
GBT & $0,81^{*}$ & 0,61 & $0,67 *$ & $0,71^{*}$ \\
ES & $0,72^{*}$ & 0,54 & $0,71^{*}$ & $0,63 *$ \\
CP & 0,40 & 0,51 & 0,60 & 0,47 \\
\hline
\end{tabular}

*significativo a $5 \%$ de probabilidade, pelo teste t.

$* *$ significativo a $1 \%$ de probabilidade, pelo teste $\mathrm{t}$.

Este procedimento, portanto, apesar de ter apresentado correlação significativa com os demais testes empregados não permitiu detectar diferenças significativas entre os lotes 1, 2 e 3, diferenciando-os apenas do lote 4, o de menor vigor. Por outro lado, a deterioração controlada por 48 horas em sementes com $24 \%$ de água (Tabela 2) permitiu a obtenção de informações correspondentes aos demais testes de vigor (Tabela 1), o que pode ser observado tanto com relação à ordenação das médias quanto pelas correlações significativas (Tabela 3). Portanto, neste caso, a 
análise de correlação mostrou-se como uma ferramenta auxiliar para confirmar as informações obtidas pela comparação entre as médias obtidas para cada lote. Segundo Marcos Filho et al. (1984), a correlação significativa indica apenas tendência de variação semelhante entre duas características, de modo que os resultados desta análise não devem ser interpretados isoladamente.

\section{CONCLUSÕES}

O teste de deterioração controlada foi eficiente para a separação dos lotes de sementes de melão quanto ao vigor. Para esta finalidade, devem ser utilizadas sementes com o grau de umidade ajustado para $24 \%$, a $45^{\circ} \mathrm{C}$, por 48 horas.

\section{REFERÊNCIAS}

ASSOCIATION OF OFFICIAL SEED ANALYSTS. Seed vigor testing handbook. East Lansing, 1983. 88p. (Contribution, 32).

BHERING, M.C.; DIAS, D.C.F.S.; GOMES, J.M.; BARROS, D.I. Métodos para avaliação do vigor de sementes de pepino. Revista Brasileira de Sementes, Londrina, v.22, n.2, p.171-175, 2000 .

BRASIL. Ministério da Agricultura e da Reforma Agrária. Regras para análise de sementes. Brasília: SNAD/DNDV/CLAV, 1992. 365p.

DIAS, D.C.F.S.; ALVARENGA, E.M. Teste de germinação a baixa temperatura. In: KRZYZANOWSKI, F.C.; VIEIRA, R.D.; FRANÇA NETO, J.B.(Ed.). Vigor de sementes: conceitos e testes. Londrina: ABRATES, 1999. p.7.1-7.3.

HAMPTON, J.G.; TEKRONY, D.N. Controlled deterioration test. In: ___ Handbook of vigour tests methods. Zürich: ISTA, 1995. p.70-78.

KRZYZANOWSKI, F.C.; VIEIRA, R.D. Deterioração controlada. In: KRZYZANOWSKI, F.C.; VIEIRA, R.D; FRANÇA NETO, J.B. (Ed.) Vigor de sementes: conceitos e testes. Londrina: ABRATES, 1999. p.6.1-6.8

MARCOS FILHO, J. Testes de vigor: importância e utilização. In: KRZYZANOWSKI, F.C.; VIEIRA, R.D.; FRANÇA-NETO, J.B. (Ed.). Vigor de sementes: conceitos e testes. Londrina: ABRATES, 1999. p.1.1-1.21.

MARCOS FILHO, J.; PERCARIN, H.M.C.; KOMATSU, Y.H.; DEMÉTRIO, C.G.B.; FANCELLI, A.L. Testes para avaliação do vigor de sementes de soja e sua relação com a emergência das plântulas em campo. Pesquisa Agropecuária
Brasileira, Brasília, v.19, n.5, p. 605-613, 1984.

MATTHEWS, S. Controlled deterioration: A new vigour test for crop seeds. In: HABBLETHWAITE, P.D. Seed Production. London: Butterworths. 1980. p.647-660.

MATTHEWS, S. ; POWELL, A.A. Controlled deterioration test. In: PERRY, D.A. (Ed.) Handbook of vigour test methods. 2.ed. Zürich: ISTA, 1987. p.49-56.

MENDONÇA, E.A.F.; RAMOS, N.P.; FESSEL, S.A.; SADER, R. Teste de deterioração controlada em sementes de brócoli (Brassica oleraceae L.) var. italica. Revista Brasileira de Sementes, Londrina, v.22, n.1, p.280-287, 2000.

MENDONÇA, E.A.F.; RAMOS, N.P.; FESSEL, S.A. Adequação da metodologia do teste de deterioração controlada em sementes de brócolis (Brassica oleracea L. var. italica). Revista Brasileira de Sementes, Londrina, v.25, n.1, p. 18-24, 2003.

NAKAGAWA, J. Testes de vigor baseados no desempenho de plântulas. In: KRZYZANOWSKI, F.C.; VIEIRA, R.D.; FRANÇA-NETO, J.B. (Ed.). Vigor de sementes: conceitos e testes. Londrina: ABRATES, 1999. p.2.1-2.21.

PANOBIANCO, M.; MARCOS FILHO, J. Comparação de métodos para avaliação da qualidade fisiológica de sementes de pimentão. Revista Brasileira de Sementes, Brasília, v.20, n.2, p.306-310, 1998.

PANOBIANCO, M.; MARCOS FILHO, J. Envelhecimento acelerado e deterioração controlada em sementes de tomate. Scientia Agrícola, Piracicaba, v.58, n.3, p.525-531, 2001.

POWELL, A.A. The controlled deterioration test. In: VENTER, H.A. (Ed.) Seed vigour testing seminar. Copenhagen: ISTA, 1995. p.73-87.

POWELL, A.A.; MATTHEWS, S. Application of the controlled deterioration vigour test to detect seed lots of Brussels sprouts with low potencial for storage under commercial conditions. Seed Science and Technology, Zürich, v.12, n.2, p.649-657, 1984.

POWELL, A.A.; MATTHEWS, S. Evaluation of controlled deterioration a new vigour test for small seeds vegetables. Seed Science and Technology, Zürich, v.9, n.2, p.633-640, 1981.

TORRES, S.B. Métodos para avaliação do potencial fisiológico de sementes de melão. Piracicaba. 2002. 103f. Tese (Doutorado em Agronomia), Escola Superior de Agricultura "Luiz de Queiroz", Universidade de São Paulo, 2002.

WANG, Y.R.; HAMPTON, J.G.; HILL, M.J. Red clover vigour testing - effects of three test variables. Seed Science and Technology, Zürich, v.22, n.1, p.99-105, 1994.

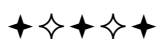

